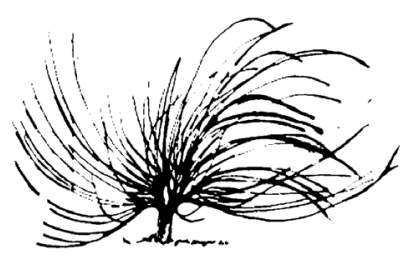

\title{
Pedagogía contestataria: propuesta para enfrentar las relaciones de poder en el escenario educativo
}

\author{
Keylor Robles Murillo ${ }^{1}$ \\ Universidad de Costa Rica \\ Costa Rica \\ robleskeylor@gmail.com
}

\begin{abstract}
Resumen
El presente ensayo tiene como objetivo principal compartir reflexiones en torno a la importancia del desarrollo de una pedagogía contestataria. Esta propuesta se fundamenta desde cinco aristas: a) epistemología, b) ontología, c) axiología, d) teleología y e) metodología. Cabe mencionar que dicha pedagogía surge a partir de la perspectiva en donde, se concibe a la educación como un producto sociocultural, y a su vez, como una alternativa para visibilizar y deconstruir las relaciones de poder que surgen en la sociedad. Finalmente, se espera que los aportes brindados puedan incidir positivamente, en las relaciones educativas con el fin de convertir la educación en un medio para lograr la transformación social.
\end{abstract}

Palabras clave: educación, pedagogía, cambio social, contestataria

Recibido: 16 de enero de 2019. Aprobado: 12 de setiembre de 2019.

http://dx.doi.org/10.15359/rep.14-2.3

1 Bachiller en Trabajo Social, Universidad de Costa Rica, Sede de Occidente. Tesiario de licenciatura en Trabajo Social, UCR. Estudiante de Enseñanza del Castellano y la Literatura, Universidad de Costa Rica, SO. Investigador asistente en la Sede de Occidente. Autor de más de diez artículos académicos publicados en Colombia, Costa Rica, México y Argentina. Autor de más de veinte artículos de opinión socializados en diversos medios divulgativos nacionales e internacionales. ORCID: https://orcid.org/0000-0002-1493-5582. 


\begin{abstract}
The main objective of this essay is to share reflections on the importance of the development of a rebellious pedagogy. This proposal is based on five aspects: a) epistemology, b) ontology, c) axiology, d) teleology and e) methodology. It should be mentioned that this pedagogy arises from the perspective where education is conceived as a sociocultural product, and in turn, as an alternative to visualize and deconstruct the power relations that arise in society. Finally, it is expected that the contributions provided can have a positive impact on educational relations in order to convert education into a means to achieve social transformation.
\end{abstract}

Keywords: Education, Pedagogy, Social change, Rebellious

\title{
Introducción
}

ntes de iniciar, es oportuno referir a que, si bien es cierto, este
ensayo expone una retórica articulada mediante un conjunto
de planteamientos; para efectos del abordaje se derivan tres subtemas fundamentales: 1) discusión sobre la importancia de concebir la educación como un proceso sociocultural enmarcado en un contexto determinado, 2) problematización de las relaciones de poder reproducidas en los escenarios educativos y 3) definición de una propuesta pedagógica para enfrentar dichas relaciones de poder, la cual incluye los fundamentos para su visibilización y desmitificación.

Primeramente, en lo que respecta a la educación ${ }^{2}$, entendida como un proceso sociocultural, se debe mencionar que la pedagogía no se puede entender descontextualizada de la realidad y del escenario en el cual se circunscribe. Esto se afirma debido a que los valores (promovidos o cuestionados), las prácticas, los discursos, las ideologías, entre otros elementos integradores de la cultura, al ser compartidos en la sociedad inciden directamente en la praxis educativa desarrollada en todos los niveles de formación.

2 Según Guerra (2011) "la educación es el criterio más amplio que abarca los procesos formales y no formales del individuo. En esta etapa la sociedad tiene un papel importante, en la medida que ella facilita los procesos de aprendizaje ya sean éstos intencionales o difusos. Aquí juega un papel importante la educabilidad del individuo. Todo proceso educativo lleva implícita la idea de formar a la persona" (p. 187). 
Tal y como afirma Picado (2001), la educación conforma un sistema sociocultural ${ }^{3}$ que interactúa con los demás componentes: económico, político, artístico, religioso, entre otros. Por esta razón, se abre constantemente hacia los diversos factores, macro y micro, influyentes en el acto o hecho educativo; es decir, lo que sucede en la cotidianidad de los procesos educativos, en todos los niveles y modalidades, se encuentra permeado por un contexto con valores y patrones socioculturales específicos.

Relacionado con lo anterior, Seas (2016), señala que el carácter dinámico y dialéctico presente en la educación, impide su funcionamiento a espaldas del medio sociocultural en que se encuentra. Lo anterior implica la incorporación constante de las necesidades en la enseñanza y el aprendizaje, suscitadas en el contexto social con la finalidad de adecuar los objetivos y reajustar el funcionamiento a los cambios producidos dentro de los escenarios educativos, según una delimitación espacial y temporal específica.

De igual manera, otro motivo por el cual la educación se considera como un proceso sociocultural, consiste en que sus fines, los cuales se espera se concreten en las estrategias didácticas y los proyectos pedagógicos desarrollados por el cuerpo docente en el ambiente áulico, suelen establecerse según los lineamientos desarrollados por el gobierno de turno. Por consiguiente, las políticas educativas se encuentran influenciadas por aspectos macroeconómicos del Estado en que se contextualiza; y a su vez, se materializan, ya sea parcial o totalmente, en el campo de la educación y su cotidianidad.

Cabe referir que lo anterior se debe analizar críticamente, pues en ocasiones esta incorporación de "intereses y necesidades" no se lleva a cabo con el fin de integrar las demandas de la sociedad civil; sino más bien con el objetivo de hegemonizar los proyectos sociopolíticos de los grupos de poder económico. Por esta razón, algunos sistemas educativos se han modificado con la intención de incorporar la lógica neoliberal: reproducción de la fuerza de trabajo, pues es la que predomina en la formulación y ejecución de políticas dentro del capitalismo tardío. Lo anterior, se evidencia en proyectos "técnico-educativos"

3 En este ensayo, la cultura se concibe como el conjunto de la información no hereditaria acumulada, conservada y que sea transmitida por los diversos grupos sociales mediante la colectividad; es decir, se puede afirmar que es un conjunto de significaciones. Por tanto, es producto de la humanidad, y a su vez, es transformable (Ron, 1977). 
como la Educación Dual ${ }^{4}$, en donde se intenta generar una tecnificación del estudiantado para garantizar su inserción al mercado laboral para responder a la demanda de "mano de obra" de las empresas.

La lógica neoliberal en la educación debe entenderse como parte del sistema capitalista preponderante en la sociedad. Según Izquierdo (1988), este sistema se define como un conjunto de relaciones sociales entre los sujetos enmarcados dentro de relaciones de explotación económica, cuya finalidad es la acumulación y la reproducción de capital. Por esta razón, se fundamenta en la separación entre trabajo y capital, en donde la burguesía controla los medios de producción y la clase trabajadora modifica las materias primas con el objetivo de producir mercancías que se inserten en la égida económica capitalista y neoliberal. Incluso la capacidad de trabajo, o fuerza de trabajo, de las personas se convierte en otra mercancía más.

Sumado a lo anterior, Giroux (1990), afirma que la escuela es reproductora y legitimadora del orden establecido en el ámbito económico, cultural, social y político, pues proporciona el conocimiento y las habilidades consideradas como necesarias a las clases y grupos sociales. Esto con el fin de que ocupen su lugar socialmente asignado, según la estratificación en clases, razas y sexos; es decir, no propone un cambio en las realidades estratificadas.

Lo anterior, se establece con la finalidad de distribuir formas de conocimiento, valores, lenguaje y estilos constituyentes de la cultura dominante y sus intereses económicos e ideológicos que subyacen al poder político del Estado. Desde estas dinámicas de poder, las personas se segregan y jerarquizan, pues se les arrebata su condición de ser humano, es decir, se deshumanizan, convirtiéndolas en objetos que respondan a la lógica del sistema hegemónico.

Comprender la educación desde su carácter sociocultural permite dimensionar las relaciones de poder como resultado de una sociedad

4 Para ampliar este tema, se puede revisar el informe realizado por el Colegio de Licenciados y Profesores en Letras, Filosofía, Ciencias y Artes (Colypro) (2015), en el cual se señalan algunas de las incongruencias en su ejecución. Por ejemplo: "En el articulado no se especifica el perfil y la formación necesaria que la persona mentora requiere (...) se debe de realizar un análisis de la población meta en función de la legislación vigente con respecto a las responsabilidades que debe cubrir el Estado en asegurar la permanencia de los mismos en el Sistema Educativo Formal (...)" (p. 11). Cabe agregar que el fin de los proyectos de educación técnica se puede percibir como positivo para la sociedad civil; no obstante, en esta ocasión, la crítica es hacia su funcionamiento. 
creadora y reproductora de valores que garantizan la opresión sufrida por parte de diversos grupos poblacionales. Del mismo modo, es oportuno indicar que anteriormente, se hizo alusión al capitalismo, pues este es uno de los sistemas, en conjunto con el racismo, el sexismo, la homofobia y la xenofobia, influyentes en el establecimiento y la reproducción de dichas dinámicas desiguales.

\section{Relaciones de poder en la educación}

Para analizar las relaciones de poder en el ámbito educativo, es fundamental entender la educación inmersa dentro de los comportamientos autoritarios que han regido a la sociedad durante los diferentes momentos históricos. Dentro de dichos comportamientos se encuentran una serie de arquetipos predominantes en cada época y coyuntura sociopolítica. Por ejemplo, el guerrero, el sacerdote, el caballero andante, el monje, el religioso jesuita, el caballero inglés, el diplomático decimonónico, el soldado y el oficial de los ejércitos modernos (Bernardini, 2010).

Cabe agregar que todos estos arquetipos se formaron con mucha eficacia al seguir criterios compartidos socialmente. Además, se basaron en perspectivas androcéntricas ${ }^{5}$, es decir, desde la mirada de los hombres y para ellos. Lo anterior, debido a que históricamente, han sido los hombres quienes han ejercido el poder en diferentes niveles, ya sea como dueños de las propiedades privadas, o bien, como el patriarca en su hogar mediante el control de su familia.

Si bien es cierto, los arquetipos construidos socioculturalmente han sufrido transformaciones, las relaciones de poder se mantuvieron como elemento en común. Para ampliar lo anterior, se pueden enfatizar los aportes de Michel Foucault sobre la conceptualización de la categoría teórica del poder. Este fue uno de los principales autores que abordó las dinámicas basadas en dicha categoría dentro de las estructuras sociales y políticas:

El ejercicio del poder no es simplemente una relación entre "parejas", individuales o colectivas; se trata de un modo de acción

5 Varela (2014), amplia la discusión sobre esta categoría cuando afirma que es "considerar al hombre como medida de todas las cosas. El androcentrismo ha distorsionado la realidad, ha deformado la ciencia y tiene graves consecuencias en la vida cotidiana. Enfocar un estudio, un análisis o una investigación desde la perspectiva masculina únicamente y luego utilizar los resultados como válidos para todo el mundo, hombres y mujeres” (p. 101). 
de algunos sobre algunos otros. Lo que es decir, desde luego, que no existe algo llamado el Poder, o el poder, que existiría universalmente, en forma masiva o difusa, concentrado o distribuido. Solo existe el poder que ejercen "unos" sobre "otros" (Foucault, 1988, p. 14).

Los planteamientos de este autor son fundamentales para desarrollar análisis críticos estructurales y sistemáticos sobre el poder, pues permiten desnaturalizar la idea de que el poder es inmutable y neutral (Ávila-Fuenmayor, 2006). En este caso, las relaciones de poder en el escenario educativo se basan principalmente en dos factores: 1) conocimiento (cognoscitivo) y 2) edad (etario). El autor de este ensayo afirma que estos son los factores principales, mas no los únicos, pues la desigualdad se agrava a partir de otras categorías tales como: sexo-género, raza, etnia, orientación e identidad sexual, condición socioeconómica. No obstante, por cuestiones de delimitar la discusión, dichas categorías no se abordan a profundidad.

En el caso del conocimiento, se percibe que "quien porta y transmite conocimiento" es la voz oficial para dirigir los procesos educativos, es decir, quien cuenta con un grado académico superior. No obstante, Assman (2002), manifiesta que la vida se caracteriza por procesos de aprendizaje constantes y permanentes. Esto refuerza la idea de que la formación es un proceso inacabado, en donde los seres humanos se encuentran en aprendizaje continuo a partir de las experiencias que vivimos (Freire, 2004). Por tanto, incluso las personas encargadas de facilitar ${ }^{6}$ el proceso educativo también, aprenden cotidianamente de la relación educativa.

De igual manera, se puede evidenciar que el poder reproduce la educación bancaria y la pedagogía tradicional problematizadas por Freire (1985 citado por Ocampo, 2008). Freire afirma que la educación bancaria no permite que las personas generen procesos de reflexión y sean conscientes del contexto sociopolítico en el que se encuentran insertas. Además, este tipo de educación considera que los educandos son

6 En este ensayo se utiliza el verbo "facilitar", pues se considera que es congruente con la propuesta pedagógica y didáctica planteada. Es importante añadir que la ruptura epistemológica, ontológica y axiológica del sistema educativo tradicional, legitimador de las relaciones de poder, también debe incorporar el uso de palabras y categorías que no reproduzcan la realidad desigual. Por tanto, el cambio de verbos transitivos no es un asunto morfosintáctico, sino un ejercicio problematizador en el nivel ético y político. 
sujetos pasivos que reciben el conocimiento que les transmite el educador o la educadora. Por consiguiente, esta relación se puede definir como monológica y unidireccional.

El segundo factor que reproduce las relaciones de poder dentro del escenario educativo es el adultocentrismo, el cual ha sido un obstáculo vigente en el sistema educativo en el nivel nacional e internacional. Según Krauskopf (2000), este tipo de discriminación se designa en nuestras sociedades capitalistas y patriarcales con una relación asimétrica y tensional de poder entre los adultos y las personas jóvenes. Esta visión del mundo se encuentra montada sobre un universo simbólico, en donde la sabiduría y el conocimiento son elementos ajenos a los jóvenes.

Lamentablemente, estas relaciones de poder pueden provocar el silencio de las voces disidentes que no coinciden con la posición del docente, generando un ambiente de opresión dentro del ambiente áulico; pues no se permite externar puntos de vista de estudiantes que discrepen con la autoridad jerárquica considerada como incuestionable. Incluso en ocasiones se ejerce un trato diferenciado, de manera negativa y discriminatoria, a las personas que tienen otras perspectivas; las cuales podrían aportar y enriquecer la discusión.

Relacionado con lo anterior, Gentili (2014), afirma que la presencia de estas relaciones de poder autoritarias y dictatoriales, pueden provocar la exclusión de estudiantes del sistema educativo; pues se sienten reprimidos. Según Castel (1997 citado por Gentili, 2014), existen tres formas cualitativamente diferenciadas de exclusión: 1) supresión completa de una comunidad mediante prácticas de expulsión o exterminio, 2) exclusión como mecanismo de confinamiento o reclusión y 3) segregar incluyendo, consiste en atribuir un estatus especial a determinada clase de individuos, es decir, crear una subciudadanía.

La última forma de exclusión, "segregar incluyendo", solapa y normaliza diferentes manifestaciones de esas prácticas excluyentes. Aunado a lo anterior, se debe recordar que las personas no son excluidas por decisión propia, pues nadie quiere ser excluido; sino más bien, este tipo de violencia segregacional es el resultado de una construcción histórica, ideológica, discursiva y moral que se reproduce mediante diversos aparatos ideológicos, tales como la familia, la iglesia, la escuela, los medios de comunicación, entre otros. 
Sin embargo, la educación también puede ser un escenario de posibilidades a través de las cuales los sujetos pueden llegar a ocupar espacios de poder en la sociedad, en vez de subordinarlos ideológica y económicamente (Giroux, 1990). Este poder se encuentra referido a un conjunto de prácticas reivindicativas que generan dinámicas sociales, las cuales conllevan a la construcción de diversas experiencias y subjetividades, en donde se les brinda mayor importancia a los educandos en el proceso de enseñanza-aprendizaje.

Por consiguiente, el estudiantado se convierte en educandos-educadores, y los educadores pasan a ser educadores-educandos ${ }^{7}$. Tal y como se evidencia, esta forma concibe a la educación de manera dialógica y bidireccional, por parte de los actores que intervienen dentro del escenario formativo. Esta premisa cimienta las bases de la pedagogía contestataria planteada en el presente ensayo, la cual se convierte en una propuesta política y educativa de resistencia ante un sistema imperante que homogeniza a todo el estudiantado.

\section{Pedagogía contestataria}

A criterio del autor de este texto, la pedagogía contestataria surge como antítesis y ejercicio de resistencia ante la influencia del capitalismo en la educación, y a su vez, como alternativa a las relaciones de poder adultocéntricas; pues su objetivo consiste en desarrollar una transformación integral dentro del sistema educativo tradicional. Por esta razón, se rescata el planteamiento de Meoño (2003), cuando manifiesta la importancia de generar un compromiso ético y político reflejado en una cultura contestataria que promueva una sociedad justa y equitativa.

A continuación, se representan los fundamentos en que se cimienta la propuesta:

7 En esta misma línea de argumentación, Robles (2017), señala que "está dentro de la capacidad del docente generar pequeños cambios, fisuras mínimas al sistema, marcar la diferencia. Cada docente tiene la oportunidad dentro de las aulas de maniobrar en la aplicación de una pedagogía diferente a la que exige el currículum educativo. Está claro que él hacerlo involucra un esfuerzo extra de los docentes, pero debe existir la esperanza de que en algún momento la lucha por el razonamiento crítico será un fin dentro del proceso educativo del país" (Robles, 2017, p. 30). 


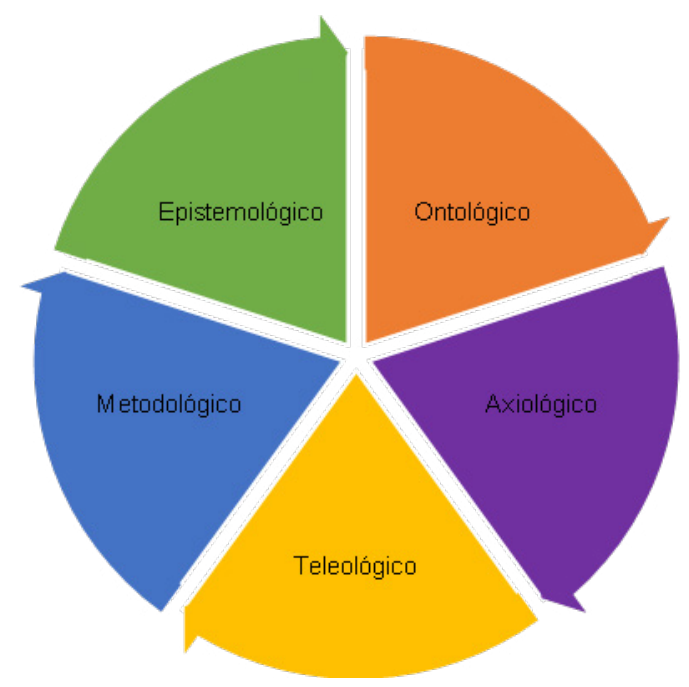

Figura 1. Fundamentación de la pedagogía contestataria Nota: elaboración propia (2019).

Antes de seguir, es importante señalar que las dimensiones de la propuesta se representan gráficamente de manera circular, pues el fin consiste en mostrar cómo la ejecución de la pedagogía contestataria debe basarse en la integralidad y el dialogismo entre todos sus fundamentos. Por tanto, no puede ser entendida de forma unidireccional, ni segregada.

\section{Fundamentos epistemológicos}

Primeramente, en lo que respecta a los fundamentos epistemológicos de la pedagogía contestataria, se debe comprender que la generación de conocimiento no es un proceso desligado de los valores predominantes en una sociedad determinada. Por tanto, no se puede considerar como neutral, pues toda decisión en materia educativa enmarca una postura ideológica y, por tanto, implica un posicionamiento específico ante un fenómeno; ya sea legitimador, indiferente o contestatario.

En este caso, la generación y la socialización del conocimiento tiene que ser congruente con la reivindicación de los derechos y la defensa de los intereses de aquellos sectores que han sido históricamente oprimidos y excluidos del sistema educativo: proletariado, mujeres, personas negras, población indígena, personas con discapacidad, entre 
otros. Esta práctica representa una postura antagonista con enfoques tradicionales presentes en el sistema educativo.

Es importante entender que la pedagogía contestataria no solamente aboga por la inclusión de los sectores excluidos dentro de las relaciones educativas, ya que esta visión limitada no superaría la inclusión formal de "segregar incluyendo" mencionada por Gentili (2014); sino también se considera trascendental que estos grupos poblacionales desempeñen un papel protagónico en la construcción del conocimiento desde las experiencias situadas. Esta última categoría se entiende como "una forma de crear significado desde las actividades cotidianas de la vida diaria" (Sagástegui, 2004, p. 31), es decir, desde los diversos campos sociales ${ }^{8}$ que conforman la vida cotidiana de las personas.

Para este fin, propongo incorporar las bases de tres enfoques epistemológicos invisibilizados por la visión positivista del conocimiento dentro de la pedagogía contestataria. Si bien es cierto, existen muchos enfoques insurgentes que plantean formas alternativas de construir conocimiento; para efectos de esta propuesta se deciden incorporar tres: 1) intercultural, 2) feminista y 3) queer. Se debe agregar que estas corrientes se enmarcan dentro de la educación inclusiva para atender la diversidad, pues tal y como afirman Ortega y Sánchez (2008):

...las expresiones de la diversidad van a estar presentes constantemente, y, por lo tanto, deben asumirse con altos niveles de compromiso. Sin embargo, las posibilidades de intervención en cuanto a este aspecto deben compaginar un amplio espectro que contradiga el uso de fórmulas universales y generales (p. 126).

En primer lugar, el enfoque intercultural afirma la existencia de un sistema racista, etnofóbico y xenófobo que ha desplazado a ciertos grupos poblacionales en la generación de conocimiento, al desvalidar los aportes teóricos y metodológicos brindados. Relacionado con lo anterior, Santos (1998), afirma que a partir de la colonización se generó un epistemicidio, el cual intenta subalternizar y marginalizar conocimientos

8 Las categorías "campo social" y "vida cotidiana" se comprenden desde los aportes de Bourdieu. En el caso de campo social se conceptualiza como una esfera de la vida social en torno a cierto tipo de relaciones e intereses propios (Bourdieu, 2000). Mientras que vida cotidiana consiste en: "un espacio de construcción donde hombres y mujeres van conformando la subjetividad y la identidad social" (Bourdieu citado por Uribe, 2014, p. 101). 
que no se circunscribieran dentro del proceso de expansión capitalista. Por tanto, la pedagogía propuesta procura llevar a cabo una ruptura epistémica con la imposición de las teorías euro y anglocéntricas9 .

En segundo lugar, el enfoque feminista se puede definir como la necesidad de ligar cualquier tipo de conocimiento a la lucha política y al movimiento feminista, buscando la liberación del pensamiento y la praxis de toda clase de opresión y desigualdad (Boscán, 2011). Por consiguiente, el proyecto político que refleja la epistemología feminista, incluye problematizar cómo las mujeres han sido expulsadas de la ciencia. Esto se articula con la creación de nuevas categorías para acercarse a la realidad estudiada, tales como la experiencia genérica situada, es decir, cada quien produce conocimiento desde el sitio en que se desenvuelve cotidianamente. Incluso, algunas autoras proponen una pedagogía popular feminista (Korol, 2007).

La tercera propuesta epistemológica incorporada en la pedagogía contestataria consiste en la queer ${ }^{10}$. Esta corriente toma como premisa inicial que la producción de conocimiento se ha desarrollado desde una lógica patriarcal, heteronormada y diversofóbica ${ }^{11}$. Además, denuncia cómo algunas ciencias se han empleado con el fin de justificar el sistema basado en los valores heteropatriarcales; incluso deshumanizando a diversos sectores poblacionales. A partir de esta realidad, plantea que en los procesos de construcción epistémica se contemple la existencia de una amplia gama de identidades y orientaciones relacionadas con la sexualidad humana; garantizando la reivindicación de las voces disidentes.

Uno de los elementos en común de los enfoques epistemológicos descritos, consiste en que todos visibilizan cómo el poder se ha convertido en un mecanismo de control ideológico, utilizado por los sectores hegemónicos, para perpetuar la dominación mediante el conocimiento institucionalizado. Lo anterior, cobra gran importancia dentro de la pedagogía propuesta, debido a que el objetivo epistemológico consiste en

9 El eurocentrismo es una postura ideológica y epistemológica que coloca a ciertos países de Europa como centro del conocimiento moderno y universal (Ramírez y Solano, 2017). En el caso del anglocentrismo se enfatiza en la producción de Estados Unidos como espacio para entender el mundo (Diuk y Ferroni, 2013).

10 Según Fonseca y Quintero (2009), el verbo transitivo queer expresa el concepto de "desestabilizar", "perturbar", "jorobar"; por lo tanto, las prácticas queer se apoyan en la noción de desestabilizar normas" (p. 45).

11 En este caso la diversofobia puede entenderse como el odio y el rechazo o la desvalorización hacia cualquier práctica, asociada con la sexualidad alternativa, distinta a la hegemonía heterosexual (Villasana, 2013). 
construir conocimiento desde otros espacios posibles, los cuales han sido invisibilizados de manera sistemática.

\section{Fundamentos ontológicos}

En lo que respecta a los fundamentos ontológicos de la pedagogía contestataria, se parte de una concepción de la realidad que puede ser vista desde distintas miradas episteontológicas, es decir, se comprende y se asume de forma diferenciada y particular a través de las subjetividades de cada persona. Esto se relaciona estrechamente con la visión de mundo que se tenga sobre la configuración de "lo real" junto con el papel que se le asigne a cada sujeto dentro del proceso de asunción y comprensión de la realidad en que se ubica.

Aunado a lo anterior, se analiza la realidad desde los planteamientos de la dialéctica, en donde ningún factor que la constituye es dado o eminentemente natural; por el contrario, se reconfigura de forma constante a partir de la tensión-contradicción de fuerzas y relaciones sociales. Cabe añadir que, a lo interno de esta dinámica social, incluido el sistema educativo, operan estructuras dominantes que prevalecen legitimadas, por medio de distintos mecanismos de control ideológico, económico, político y cultural de la sociedad ${ }^{12}$.

En este sentido, es fundamental reivindicar el papel que ha tenido la educación a lo largo de la historia; principalmente, enfatizando en los procesos de lucha y resistencia llevados a cabo por sujetos activos que han logrado posicionar la educación como un medio para la transformación social. Tal es el caso del movimiento estudiantil en Francia, México, Argentina, Nicaragua, Chile, Colombia y Costa Rica. Esto incluye comprender que el estudiantado, el cual es protagonista y sujeto político, cuenta con la capacidad de incidir y modificar su propia realidad, a partir de sus propios procesos de ruptura epistemológica y ontológica.

Cabe señalar que el fundamento ontológico se torna medular dentro de la propuesta pedagógica, debido a que uno de los propósitos primarios, tal y como se mencionó anteriormente, refiere a la validación de las experiencias situadas por parte del estudiantado; pues las situaciones vividas y su relato es una forma de legitimar su conocimiento.

12 Tres de estas estructuras consisten en los siguientes sistemas de dominación: patriarcado, capitalismo y etnocentrismo. 
Por tanto, se reafirma la necesidad de ser sujetos de conocimiento que reconstruyen sus propios procesos educativos.

\section{Fundamentos axiológicos}

Por otra parte, en esta misma línea de argumentación, se encuentran los fundamentos axiológicos de la pedagogía propuesta. Cabe mencionar que para efectos de este ensayo la axiología educativa, o pedagogía axiológica, se entiende como el conjunto de valores en el nivel ético y político que debe orientar a la educación, la práctica educativa, y a su vez, repercutir positivamente, en el estudiantado y el cuerpo docente participante en el ambiente áulico (Manjón, 1996).

En este caso, se considera que algunos de los valores que deben direccionar la praxis educativa son los siguientes: igualdad, equidad, respeto, empatía, compromiso, solidaridad, resistencia, diversidad, sororidad, redistribución y justicia social. Dichos valores se construyen desde posturas éticas y políticas que abogan por la transformación social y el cumplimiento de los derechos humanos en la educación, y las demás esferas de la vida social, tales como el marxismo, el socialismo, el feminismo, la interculturalidad y los estudios queer.

\section{Fundamentos teleológicos}

Posteriormente, en este punto se explicitan los fundamentos teleológicos que sustentan la pedagogía contestataria. Para comprender el origen de los fundamentos planteados, se deben revisar los fines de la educación dentro del sistema educativo capitalista. Según León (2012):

El ideal de la educación capitalista es la reproducción de las clases sociales sobre la base de la posesión de bienes materiales, el desarrollo de competencias científicas, tecnológicas, económicas y empresariales para satisfacer las necesidades y deseos individuales, atributos importantes de una sociedad competitiva (p. 7).

Ante esta realidad individualista definida por una educación basada en fortalecer competencias que responden a los intereses de la lógica capitalista, se considera fundamental desarrollar un giro teleológico hacia un sistema educativo que busque eliminar las inequidades, y a su vez, tome como base la justicia social. Para este fin, es pertinente comprender el sistema educativo como un proceso sociocultural y 
colectivo, pues partir de este punto facilita la construcción de fines y propósitos acordes con la ciudadanía; sin distinción alguna.

En la propuesta abordada en este ensayo se decide integrar el proyecto societal explicitado por Freire (1971), en la pedagogía del oprimido, es decir, el fin primordial de la educación debe relacionarse con fortalecer la liberación del pueblo. Esta liberación contempla acciones contestatarias y reivindicativas ante los diversos sistemas de dominación vigentes en la sociedad. Por tanto, es fundamental que el proceso formativo brinde herramientas a los actores participantes, para generar rupturas con el orden hegemónico.

\section{Fundamentos metodológicos}

Finalmente, en lo que concierne a los fundamentos metodológicos de la pedagogía contestataria, se debe señalar que el objetivo no se relaciona con definir una metodología estática y universal; sino al contrario, la intención consiste en plantear bases orientadoras que permitan al cuerpo docente facilitar los procesos educativos de manera congruente con los fundamentos señalados anteriormente. Por consiguiente, cada proceso formativo se debe planificar desde las particularidades (contexto, actores: docente, estudiantes, y recursos) que determinan la praxis educativa.

Uno de los elementos propuestos consiste en desarrollar estrategias didácticas innovadoras que replanteen la forma en cómo se construyen los aprendizajes significativos y el conocimiento. Si bien es cierto, el sistema educativo se caracteriza por su estructura rígida, si se desea trascender, la persona docente deberá realizar un esfuerzo extra para incorporar fundamentos metodológicos que encaucen el proceso formativo hacia la transformación social.

Bajo el planteamiento señalado anteriormente, es fundamental tomar en cuenta la diversidad durante el ejercicio de la acción educativa; específicamente, al incorporar la motivación en el estudiantado. Lo anterior permite que el estudiantado logre encontrar sintonía y vinculación personal-educativa para interiorizar los contenidos programáticos propuestos. Esto genera procesos de aprendizaje desde sus visiones y realidades contextuales particulares.

Sumado a lo anterior; cuando una persona docente formula y diseña un planeamiento o una propuesta programática integradora de las necesidades específicas del estudiantado y la diversidad que les caracteriza, es más probable que se logren alcanzar los objetivos definidos 
inicialmente. Cabe agregar que un planeamiento no puede realizarse de manera unívoca e invariable, sino tal y como se ha venido mencionado en el presente ensayo, debe partir desde el escenario en el que se inserta para alcanzar los resultados esperados.

Del mismo modo, es pertinente señalar que la curiosidad ${ }^{13}$, también debe convertirse en un aspecto fundamental para propiciar el desarrollo y construir conocimientos en los procesos formativos. Esta curiosidad es el motivo por el cual surgen interrogantes a las que se desea hallar una respuesta. Por tanto, implica que las personas participantes en el proceso logren comprender que entre mayor cantidad de preguntas se formulen y las sometan a comprobación, más conocimientos construyen de diferentes índoles que les permite tener una formación integral.

La inclusión de la curiosidad como elemento metodológico permite entender que la persona docente no tiene todo el conocimiento, ya que este es dialéctico. Por esta razón, el estudiantado que desarrolle la curiosidad, podrá acercarse a diferentes puntos teóricos, epistemológicos y ontológicos, para comprender los fenómenos estudiados en las múltiples áreas de aprendizaje y conocimiento. Respecto a lo anterior, es importante reflexionar sobre las maneras en cómo se puede incentivar la curiosidad en el estudiantado.

Tal y como se señaló, los elementos metodológicos propuestos, también cuentan con una fundamentación epistemológica y ontológica, debido a que la dimensión metodológica de las propuestas pedagógicas no puede desligarse de la reflexión teórica; pues definir estrategias didácticas desvinculadas de la conceptualización, provoca que la praxis educativa se reduzca a activismo. Por tanto, la propuesta expuesta en esta oportunidad se representa de manera circular y no lineal, ya que debe ser entendida dialécticamente y no de forma unidireccional.

\section{Conclusiones generales}

La educación al ser un proceso sociocultural se circunscribe dentro de un contexto societal con particularidades políticas, culturales, económicas y sociales que inciden en las relaciones educativas. Por tanto, los valores predominantes en la sociedad se encuentran materializados mediante las políticas educativas emitidas; pues todas las

13 Freire (2004) define la curiosidad epistémica como la inquietud de indagar con el objetivo de lograr develamientos 
decisiones en materia de educación encierran un conjunto de intereses específicos; los cuales pueden reproducir la lógica de desigualdad imperante e inherente al sistema capitalista.

Ante esta realidad, se considera que el carácter sociocultural, también permite desarrollar transformaciones que conviertan la educación en herramienta para la búsqueda de una sociedad equitativa y basada en la justicia social. A partir de este planteamiento surge la pedagogía contestataria. Esta propuesta aboga principalmente, por un sistema educativo que permita al estudiantado entenderse como constructor de conocimiento desde su subjetividad.

Uno de los principales aportes de esta pedagogía consiste en articular elementos de corrientes y posturas críticas con el fin de no fragmentar la realidad. Por esta razón, se afirma que existen dos sistemas de dominación: patriarcado y capitalismo que se hegemonizan dentro de la sociedad y generan las inequidades centrales. Sin embargo, no se pueden dejar por afuera las contribuciones de diversos enfoques epistemológicos insurgentes que permiten comprender que la educación debe transformar las múltiples relaciones de opresión. Cabe mencionar que este es uno de los elementos que diferencia esta propuesta de otras que han caído en el reduccionismo.

Finalmente, en este ensayo se definen cinco fundamentos para la pedagogía contestataria: a) epistemológico: integración de tres epistemologías insurgentes: intercultural, feminista y queer, b) ontológico: seres cognoscentes con capacidad transformadora, c) axiológico: valores disidentes basados en la justicia social, d) teleológico: el fin de la educación debe ser derribar los sistemas de dominación, y e) metodológico: propuestas didácticas que resignifiquen la relación entre los educandos y el educador.

\section{Referencias}

Assman, H. (2002). Placer y ternura en la educación. Hacia una sociedad aprendiente. Madrid, España: Narcea S. A. Editores.

Ávila-Fuenmayor, F. (2006). El concepto de poder en Michel Foucault. Telos, 8(2), 215-234. Recuperado de https://www.redalyc.org/articulo.oa?id $=99318557005$

Bernardini, A. (2010). La educación en valores hoy en día: entre conciencia crítica y respuestas constructivas. Innovaciones 
educativas, 17(12), 11-22. Recuperado de https://investiga.uned. ac.cr/revistas/index.php/innovaciones/article/view/559

Boscán, A. (2011). Perspectivas epistemológicas y metodológicas de la investigación feminista. Opción: Revista de Ciencias Humanas y Sociales, 65(1), 160-182. Recuperado de http://www.redalyc. org:9081/articulo.oa?id=31021901009

Bourdieu, P. (2000). Cosas dichas. Barcelona: Gedisa.

Colegio de Licenciados y Profesores en Letras, Filosofía, Ciencias y Artes (Colypro). (2015). Informe de proyecto de ley sobre la educación dual en Costa Rica. Recuperado de http:// www.colypro.com/ee_uploads/documentos/Informe_Proyecto de_Ley_final.pdf

Diuk, B. y Ferroni, M. (2013). ¿Anglocentrismo en los modelos de adquisición lectora? Un estudio en una lengua de ortografía transparente. Summa Psicológica, 10(2), 29-39. Recuperado de https://summapsicologica.cl/index.php/summa/article/view/138

Fonseca, C. y Quintero, M. (2009). La Teoría Queer: la de-construcción de las sexualidades periféricas. Sociológica, 24(69), 43-60. Recuperado de http://www.scielo.org.mx /pdf/soc/v24n69/v24n69a3.pdf

Foucault, M. (1988). El sujeto y el poder. Revista mexicana de sociología, 50(3), 3-20. Recuperado de http://terceridad.net/wordpress/ wp-content/uploads/2011/10/Foucault-M.-El-sujeto-y-el-poder.pdf

Freire, P. (1971). Pedagogía del oprimido. Buenos Aires: Siglo XXI.

Freire, P. (2004). Pedagogía de la autonomía. Sao Paulo: Paz y Tierra.

Gentili, P. (2014). La exclusión y la escuela: el apartheid y la politica de ocultamiento. Brasil: Universidad de Río de Janeiro.

Giroux, H. (1990). Los profesores como intelectuales. Hacia una pedagogía crítica del aprendizaje. Barcelona: Ediciones Paidós.

Guerra, Y. (2010). Reflexiones a propósito de la educación. La enseñanza, la pedagogía y la didáctica. Revista Educación y Desarrollo Social, 4(1), 184-195. Recuperado de https://revistas.unimilitar. edu.co/index.php/reds/article/view/928

Guerrero, P. (2002). La cultura: estrategias conceptuales para entender la identidad, la diversidad, la alteridad y la diferencia. Quito: Editorial Abya Yala.

Izquierdo, M. J. (1998). El malestar en la desigualdad. Madrid: Cátedra. 
Korol, C. (2007). Hacia una pedagogía feminista. Géneros y educación popular. Buenos Aires: Editorial El Colectivo.

Krauskopf, D. (2000). Participación social y desarrollo en la adolescencia. San José: UNFPA.

León, A. (2012). Los fines de la educación. Orbis Revista Científica de Ciencias Humanas, 8(23), 4-50.

Manjón, J. (1996). La axiología y su relación con la educación. Cuestiones pedagógicas: Revista de Ciencias de la Educación, 4(12), $151-168$.

Meoño, R. (2003). Escuela y poder: un enfoque contestatario. Ensayos Pedagógicos, 2(1), 39-56. Recuperado de https://dialnet.unirioja. es/servlet/articulo? codigo $=5409377$

Ocampo, J. (2008). Paulo Freire y la pedagogía del oprimido. Revista Historia de la Educación Latinoamericana, 10(1), 57-72. Recuperado de https://www.redalyc.org/html/869 /86901005/

Ortega, E. y Sánchez, J. (2008). Pedagogía de la diversidad: elementos que la fundamentan. Sapiens. Revista Universitaria de Investigación, 8(1), 123-135. Recuperado de https://biblat.unam.mx/es/revista/sapiens/articulo/ pedagogia-de-la-diversidad-elementos-que-la-fundamentan

Picado, F. (2001). Didáctica general. San José: EUNED.

Ramírez, J. y Solano, S. (2017). Racismo y antirracismo en literatura. Lectura etnocrítica. San José: Editorial Arlekín.

Robles, A. (2017). Sistema educativo costarricense: ¿puerta o barrera para el pensamiento crítico? Revista Ensayos Pedagógicos, 17(2), 17-31. Recuperado de http://revistas.una.ac.cr/index.php/ ensayospedagogicos/article/view/10097/12282

Ron, J. (1977). Sobre el concepto de cultura. Quito: Instituto Andino de Artes Populares.

Sagástegui, D. (2004). Una apuesta por la cultura: el aprendizaje situado. Revista Electrónica Sinéctica, 24(1), 30-39. Recuperado de https://www.redalyc.org/pdf/998/998159180 05.pdf

Santos, B. (1998). De la mano de Alicia: lo social y lo político en la posmodernidad. Bogotá: Siglo del Hombre Editores.

Seas, J. (2016). Didáctica general. Costa Rica: EUNED. 
Uribe, M. (2014). La vida cotidiana como espacio de construcción social. Procesos históricos, 25(1), 100-113. Recuperado de https:// www.redalyc.org/pdf/200/20030149005.pdf

Varela, N. (2014). Feminismo para principiantes. Zaragoza: Tititivillus. Villasana, E. (2013). Diversofobia, violencia y derecho a la salud y al trabajo. Revista Salud de los Trabajadores, 1(21), 8792. Recuperado de https://www.redalyc.org/articulo.oa?id $=375839306008$ 
